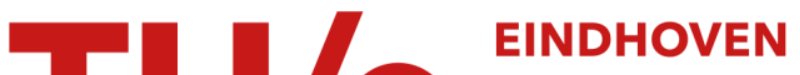 \\ UNIVERSITY OF \\ TECHNOLOGY
}

\section{Capacity flexibility allocation in an outsourced supply chain with reservation}

Citation for published version (APA):

Boulaksil, Y., Grunow, M., \& Fransoo, J. C. (2009). Capacity flexibility allocation in an outsourced supply chain with reservation. (BETA publicatie : working papers; Vol. 299). Technische Universiteit Eindhoven.

Document status and date:

Published: 01/01/2009

\section{Document Version:}

Publisher's PDF, also known as Version of Record (includes final page, issue and volume numbers)

\section{Please check the document version of this publication:}

- A submitted manuscript is the version of the article upon submission and before peer-review. There can be important differences between the submitted version and the official published version of record. People interested in the research are advised to contact the author for the final version of the publication, or visit the $\mathrm{DOI}$ to the publisher's website.

- The final author version and the galley proof are versions of the publication after peer review.

- The final published version features the final layout of the paper including the volume, issue and page numbers.

Link to publication

\section{General rights}

Copyright and moral rights for the publications made accessible in the public portal are retained by the authors and/or other copyright owners and it is a condition of accessing publications that users recognise and abide by the legal requirements associated with these rights.

- Users may download and print one copy of any publication from the public portal for the purpose of private study or research.

- You may not further distribute the material or use it for any profit-making activity or commercial gain

- You may freely distribute the URL identifying the publication in the public portal.

If the publication is distributed under the terms of Article $25 \mathrm{fa}$ of the Dutch Copyright Act, indicated by the "Taverne" license above, please follow below link for the End User Agreement:

www.tue.nl/taverne

Take down policy

If you believe that this document breaches copyright please contact us at:

openaccess@tue.nl

providing details and we will investigate your claim. 


\title{
Capacity flexibility allocation in an outsourced supply chain with reservation
}

\author{
Y. Boulaksil ${ }^{1}$, M. Grunow ${ }^{2}$, J.C. Fransoo ${ }^{1}$ \\ ${ }^{1}$ School of Industrial Engineering, Eindhoven University of Technology, The Netherlands \\ ${ }^{2}$ Department of Management Engineering, Technical University of Denmark
}

\begin{abstract}
We consider a contract manufacturer that serves a limited number of outsourcers (customers) on a single capacitated production line. The outsourcers have different levels of demand uncertainty and the contract manufacturer faces the question how to allocate the contractual capacity flexibility in an optimal way. The contractual capacity flexibility is a contract parameter that sets the amount of demand the contract manufacturer is obliged to accept from the outsourcers. We develop a hierarchical model that consists of two decision levels. At the tactical level, the contract manufacturer allocates the capacity flexibility to the different outsourcers by maximizing the expected profit. Offering more flexibility to the more uncertain outsourcer generates higher expected revenue, but also increases the expected penalty costs. The allocated capacity flexibilities (determined at the tactical level) are input parameters to the lower decision level, where the operational planning decisions are made and actual demands are observed. We perform a numerical study by solving the two-level hierarchical planning problem iteratively. We first solve the higher level problem, which has been formulated as an integer program, and then perform a simulation study, where we solve a mathematical programming model in a rolling horizon setting to measure the operational performance of the system. The simulation results reveal that when the acceptance decision is made (given the allocated capacity flexibility decision), priority is given to the less uncertain outsourcer, whereas when the orders are placed, priority is given to the most uncertain outsourcer. Our insights are helpful for contract manufacturers when having contract negotiations with the outsourcers. Moreover, we show that hierarchical integration and anticipation are required, especially for cases with high penalty cost and tight capacities.
\end{abstract}




\section{Introduction}

In the last few years, outsourcing is increasingly developing in many industries (e.g. Liston et al., 2007). The rise of contract manufacturers that often serve a number of competing outsourcers, results in new challenges and complexities. Due to shorter life cycles, need for innovation, and increased competition between the outsourcers, the contract manufacturers are challenged to increase the level of reactivity, responsiveness and to act more proactively. Therefore, contract manufacturers are more under the pressure to redesign the contractual decisions to deal with new and increased level of (demand) uncertainties.

These capabilities are often referred to as flexibility, which has been widely discussed among researchers and practitioners (Sethi and Sethi, 1990; D'Souza and Williams, 2000; Bertrand, 2003; Slack, 2005). Flexibility is also increasingly recognized by researchers and practitioners as an important performance measure of a company (De Toni and Tonchia, 2001) and of a supply chain (Duclos et al., 2003; Sanchez and Perez, 2005). This literature also addresses the limited academic research with respect to the performance impact of supply chain flexibility (Beamon, 1999).

This paper deals with the determination of contractual flexibilities from a contract manufacturer's perspective that has a long-term relationship with a number of outsourcers with different levels of demand uncertainty. The contract manufacturer negotiates with the outsourcers individually on the flexibilities, assuming that the outsourcer is willing to pay more for additional allocation of capacity flexibility. We model the contractual flexibilities explicitly, provide an approach to quantify the performance potentials, and optimize the allocation of contractual flexibilities by formulating and optimizing an integer programming problem, which anticipates on the operational performance.

Figure 1 shows the supply chain structure that we are considering in this paper. The contract manufacturer produces for all outsourcers on the same capacitated production line and does not have its own product portfolio, nor does it have inventory ownership. The contract manufacturer produces by offering outsourcing services to the outsourcers, based on orders from the outsourcers and contractual obligations. We study this make-to-order system from the contract manufacturer's perspective that faces the task of controlling its capacity in an optimal way. The outsourcers have different levels of demand uncertainty and the more uncertain an outsourcer, the more he is willing to pay the contract manufacturer for an additional unit of capacity flexibility. On the other hand, the more flexibility offered, the higher the probability that the contract manufacturer will not be able to produce all future orders, which results in (high) penalty costs, as defined in the contract.

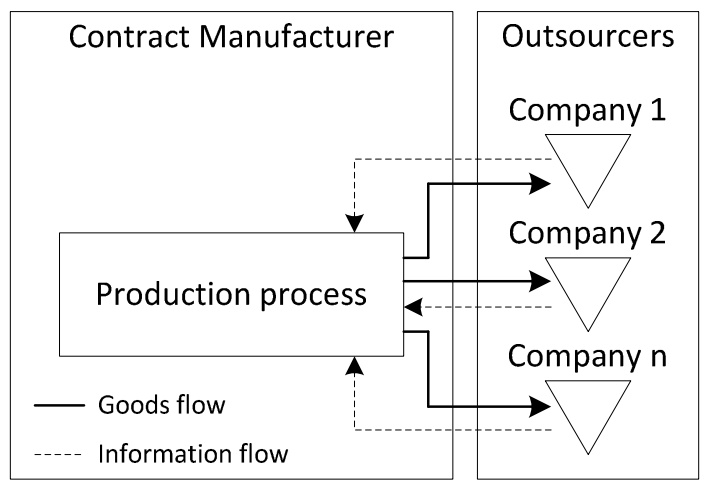

Figure 1. The supply chain structure under study

The allocation of capacity flexibility is a medium-term tactical decision that the contract manufacturer makes (e.g. once a year) when having contract negotiations. This allocation decision results in a parameter setting that is input to the short-term periodic operational planning model 
and which anticipates on the operational planning process. The operational planning process is as follows. The contract manufacturer requires that all outsourcers share their advance demand information prior to ordering, which is considered as capacity reservation. Based on the contract manufacturer's capacity planning and the allocated capacity flexibilities, the reservations are either accepted or (partly) rejected. The accepted quantities are an upper bound for the order quantities that follow afterwards. Basically, the more flexibility allocated to an outsourcer, the more reservations will be accepted from that outsourcer.

We develop a hierarchical model (see Figure 2) with two decision levels, which reflects current industry practice. At the higher decision level, the contract manufacturer decides on the allocation of capacity flexibility. At this level, the capacity level and the number of outsourcers are given as a result of a higher-level strategic decision that is beyond the scope of this study. Besides the capacity level and the number of outsourcers, some other parameters are also input to the capacity flexibility allocation decision: the levels of demand uncertainty of the outsourcers and the revenue and cost structure. We assume that this information is available at the contract negotiations. At this decision level, the expected profit function is maximized by making a trade-off between the extra revenue that is generated by increasing the allocation of capacity flexibility and the penalty costs, which result when the contract manufacturer is not able to produce all (future) orders. Moreover, the higher level model anticipates on the performance at the operational planning level.

The output of the higher decision level is the allocation of capacity flexibility for each outsourcer which is an input parameter for the lower decision level. At the lower decision level, short-term (say monthly) acceptance and production decisions are made. The acceptance decision is crucial and it should anticipate the uncertainties from the outsourcers. The allocated capacity flexibilities from the higher decision level are meant to help in the anticipation of the operational planning decisions. When the acceptance and production decisions are made, the operational performance of the system can be measured and compared with the higher level (expected) performance. We will see that there are some inconsistencies between the two decision levels. Therefore, feedback is given from the lower decision level to the higher decision level, which helps the higher decision level to anticipate on the performance at the lower decision level. In section 3.3, we discuss how this feedback is modeled and in section 5 , we will see that ignoring this feedback results in large errors.

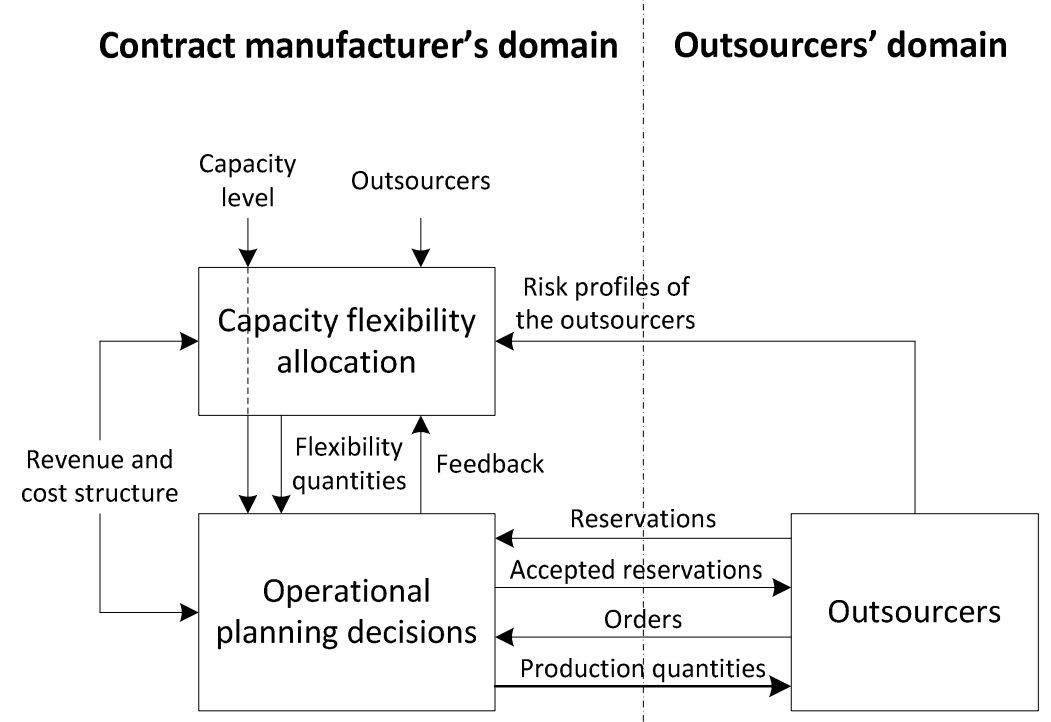

Figure 2. Two-stage hierarchical model 
This paper is organized as follows. The next section discusses the literature review. In section 3 , we develop the formal model for the hierarchical planning problem. Then, in section 4 , we present the results of the numerical study. In section 5 , we discuss the inconsistency between the two decision levels. Finally, in section 6 , we draw the conclusions and discuss some managerial insights.

\section{Literature review}

In the last two decades, a large number of papers appeared on production flexibility in the Operations Management literature (cf. Bertrand, 2003). We do not intend to provide a complete review of this literature, but we shortly review some related work and discuss our contribution to the literature. From a supply chain perspective, flexibility has mainly been studied by addressing the question whether and to what extent a certain contract coordinates the supply chain (Tsay, 1999; Cachon and Lariviere, 2005). In this stream of the literature, no explicit evaluation of the flexibilities is done and mainly a single product or a single customer is considered, which means that the implication of different customers competing for a joint capacity has not been considered.

From a more operational perspective, the measurement of production flexibility has been studied intensively. Production flexibility has a lot of measures and dimensions (D'Souza and Williams, 2000; Bertrand, 2003) and has been studied in the literature as a strategy to deal with innovation, uncertainties, short life cycles, and increased competition (Frazelle, 1986; Gupta and Goyal, 1989; Sethi and Sethi, 1990; Beach et al., 2000; Bish et al., 2005; Slack, 2005). This literature characterizes different types and measures of flexibilities, but does not model it formally to decide on the optimal level of flexibility.

Van Mieghem (1998) focuses on determining the optimal investment decisions on flexible capacity at the strategic or tactical level, under the assumption of a single production period. In Bish et al. (2005), the management of flexible capacity in a dynamic make-to-order environment is studied, where the focus is on the allocation of products to the different production plants. This line of research does not consider the operational implications of the flexibility decisions taken at higher level for a joint production capacity. Therefore, the question remains how to optimally use the production flexibility to deal with short-term demand uncertainty in a make-to-order environment.

Finally, most approaches in the literature on production flexibility consider the demand side as given, either deterministic or stochastic. In our case, we also consider the demand distributions as given, but the demand can be 'controlled' by the flexibility allocation decisions and the contractual design with the outsourcers.

\section{Model formulation}

In this section, we discuss the formulation of the two-level hierarchical planning model (see Figure 2). For the higher decision level, we develop an integer programming model which solves the flexibility allocation problem under uncertainty to optimality. This level also anticipates on the lower decision level. The output of this level is input to the lower level, where the acceptance and production decisions are made after observing the reservations and orders from the outsourcers. Based on these observations, we can measure the performance of the system. At both levels, we assume penalty costs for lost demand, as defined in the contract between the outsourcers and the contract manufacturer. Moreover, we also discuss the consistency between the two decision levels. 


\subsection{Capacity flexibility allocation}

In this section, we present the mathematical model for the higher decision level of the hierarchical planning model (see Figure 2) at which the contract manufacturer decides on the optimal allocation of capacity flexibilities. Capacity flexibility is a contract parameter that sets the amount of demand the contract manufacturer is obliged to accept from the outsourcers. This is considered as a tactical decision, made for the medium-term (e.g. one year).

Table 1. Used symbols

\begin{tabular}{|c|c|}
\hline $\begin{array}{l}C \\
D_{j} \\
D_{s} \\
\theta_{j} \\
\theta_{s} \\
\mu_{j} \\
\mu_{j}^{\prime} \\
\mu_{s} \\
\mu_{s}^{\prime} \\
f_{j}(x) \\
f_{j}^{\prime}\left(x \mid \varepsilon_{j}\right) \\
f_{s}(x) \\
f_{s}^{\prime}(x \mid \vec{\varepsilon}) \\
J \\
\varepsilon_{j} \\
\vec{\varepsilon} \\
\sigma_{j} \\
\tau_{j} \\
\tau_{s} \\
\beta \\
\pi(\vec{\varepsilon}) \\
t \\
j \\
r_{j}(t) \\
a_{j}(t) \\
q_{j}(t) \\
p_{j}(t) \\
\rho_{t} \\
\rho \\
\alpha_{j}(t) \\
\alpha_{j} \\
\gamma_{j}(t) \\
\gamma_{j} \\
M \\
\delta \\
\mathbb{Z}^{+} \\
\xi(t) \\
\psi_{j}(t) \\
\end{array}$ & $\begin{array}{l}\text { capacity level (of the contract manufacturer) } \\
\text { demand from outsourcer } j \text { (discrete random variable) } \\
\text { demand from all outsourcers (discrete random variable) } \\
\text { guaranteed demand to be accepted from outsourcer } j \\
\text { guaranteed demand to be accepted from all outsourcers } \\
\text { expected demand from outsourcer } j \\
\text { updated expected demand from outsourcer } j \\
\text { expected demand from all outsourcers } \\
\text { updated expected demand from all outsourcers } \\
\text { probability mass function of demand from outsourcer } j \\
\text { updated probability mass function of demand from outsourcer } j \text { given } \varepsilon_{j} \\
\text { probability mass function of demand from all outsourcers } \\
\text { updated probability mass function of demand from all outsourcers given } \vec{\varepsilon}_{j} \\
\text { number of outsourcers served by the contract manufacturer } \\
\text { capacity flexibility allocated to outsourcer } j \\
\text { allocation of capacity flexibility to all outsourcers } \\
\text { standard deviation of demand from outsourcer } j \\
\text { unit revenue generated from outsourcer } j \\
\text { total revenue generated from all outsourcers } \\
\text { unit penalty cost } \\
\text { expected profit function } \\
\text { time period } \\
\text { outsourcer (subscript) } \\
\text { reservation from outsourcer } j \text { in time period } t \\
\text { accepted reservation for outsourcer } j \text { in time period } t \\
\text { order quantity from outsourcer } j \text { in time period } t \\
\text { production quantity for outsourcer } j \text { in time period } t \\
\text { capacity utilization in time period } t \\
\text { expected capacity utilization } \\
\text { acceptance rate in time period } t \\
\text { expected acceptance rate } \\
\text { service level in time period } t \\
\text { expected service level } \\
\text { a big number } \\
\text { consistency factor } \\
\text { non-negative integer number } \\
\text { amount of demand that can be still accepted from the outsourcers in time period } t \\
\text { not (yet) accepted reservation quantity from outsourcer } j \text { in time period } t\end{array}$ \\
\hline
\end{tabular}

The contract manufacturer has a fixed production capacity $C$ and serves $J$ outsourcers with different levels of demand uncertainty, i.e., with different probability functions of the demand $f_{j}(x)$. The ideal situation is to have the capacity $C$ fully utilized when orders are placed. However, before orders 
are placed, outsourcers reserve capacity at the contract manufacturer which is responded to with the acceptance decision. The order quantity that follows after the acceptance decision cannot exceed the acceptance quantity. Therefore, the acceptance decision is crucial and should anticipate and incorporate the risk that the order quantity can be lower than the accepted reservation quantity, knowing that that risk is different for the different outsourcers. Therefore, at the tactical level, the capacity flexibility $\left(\varepsilon_{j}\right)$ is determined for each outsourcer $j$, such that the profit of the production line is maximized, and which is an input parameter to the operational planning level. Below, we discuss how the allocation of capacity flexibility is determined and optimized.

The demand $D_{j}$ from outsourcer $j$ is discrete and a random variable and has the probability mass function $f_{j}(x)$, which is assumed to be known to the contract manufacturer, based on e.g. historical data. Demand reflects the reservation and order quantities. We assume that each unit of demand corresponds to one unit of capacity consumption and that the demands from the different outsourcers $j$ are independently distributed. Therefore, the total demand from all outsourcers $D_{s}$ has the probability mass function $f_{s}(x)$ with $\mu_{s}=\sum_{j=1}^{J} \mu_{j}$ and $\sigma^{2}\left(D_{s}\right)=\sum_{j=1}^{J} \sigma^{2}\left(D_{j}\right)$.

The idea is that the contract manufacturer will accept only a limited part of the demand uncertainties from the outsourcers, which is expressed by the acceptance decision at the operational level. In the long-run, the average demand accepted from outsourcer $j$ should be at least equal to the expected demand $\mu_{j}$ from that outsourcer. Therefore, we introduce $\theta_{j}=\mu_{j}+\varepsilon_{j}$, which is the guaranteed demand the contract manufacturer will accept from outsourcer $j$, with $\varepsilon_{j} \in \mathbb{Z}^{+}$is the flexibility allocated and offered to outsourcer $j$. The guaranteed demand is the part of the demand the contract manufacturer will always accept. The contract manufacturer is not obliged to accept demand larger than $\theta_{j}$.

The flexibility $\varepsilon_{j}$ offered to outsourcer $j$ (with $\sigma_{j}$ ) is appreciated by the outsourcers and we assume that the outsourcers are willing to pay an additional amount for each unit $\varepsilon_{j}$. We consider a unit revenue function $\tau_{j}\left(\varepsilon_{j}, \sigma_{j}\right)$ that is increasing in $\varepsilon_{j}$ and $\sigma_{j}$, i.e., the more uncertain outsourcer is willing to pay more for an additional $\varepsilon_{j}$. The outsourcers are willing to pay additionally for the allocated capacity flexibilities, because otherwise, they would have to keep more inventories at the more downstream stages to buffer against the limited capacity availability.

By introducing $\varepsilon_{j}$, we truncate the demand distribution by updating $P\left\{D_{j}=\theta_{j}\right\}:=1-\sum_{i=0}^{\theta_{j}-1} P\left\{D_{j}=\right.$ i\} and $P\left\{D_{j}>\theta_{j}\right\}=0$. Hence, we get an updated probability mass function $f_{j}^{\prime}\left(x \mid \varepsilon_{j}\right)$ for the demand (see Figure 3 for an example). All demand larger than $\theta_{j}$ is not necessarily accepted and therefore the distribution is truncated at $\theta_{j}$, resulting in a probability mass function $f_{j}^{\prime}\left(x \mid \varepsilon_{j}\right)$ with an updated $\mu_{j}^{\prime}=\sum_{i=0}^{\theta_{j}} i \cdot P\left\{D_{j}=i\right\}$.

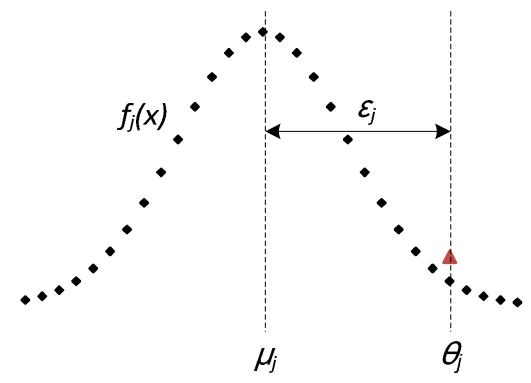

Figure 3. The original and updated probability functions for the demand 
Hence, the total expected revenue $\tau_{s}$ the contract manufacturer generates is given by (1).

$$
\tau_{s}=\sum_{j=1}^{J} \tau_{j}\left(\varepsilon_{j}, \sigma_{j}\right) \cdot \mu_{j}^{\prime}
$$

By updating the individual demand distributions of the different outsourcers, we also get an updated probability function of the total demand $f_{s}^{\prime}(x \mid \vec{\varepsilon})$ and an updated $\theta_{s}=\sum_{j} \theta_{j}$. By offering more capacity flexibility to the outsourcers, the probability that not all demand can be fulfilled, i.e. not all orders can be produced increases, which results in penalty costs. If the unit penalty cost is $\beta$, the expected penalty costs are given by (2).

$$
\beta \sum_{x=C+1}^{\theta_{s}} x f_{s}^{\prime}(x \mid \vec{\varepsilon})
$$

Both the revenue and the cost side are a function of $\overrightarrow{\varepsilon_{j}}$, which are the decision variables of the integer programming model. Therefore, a trade-off has to be made between the extra revenue that is generated by offering more flexibility $\varepsilon_{j}$ and the increased penalty costs. The objective of the model is to maximize the (non-linear) expected profit function $\pi(\vec{\varepsilon})$ and to determine the optimal $\vec{\varepsilon}=\left\{\varepsilon_{j}\right\} \in \mathbb{Z}^{+}, \forall j \in J$.

$$
\operatorname{Max} \pi(\vec{\varepsilon})=\left(\sum_{j=1}^{J} \tau_{j}\left(\varepsilon_{j}, \sigma_{j}\right) \mu_{j}^{\prime}-\beta \sum_{x=C+1}^{\theta_{s}} x f_{s}^{\prime}(x \mid \vec{\varepsilon})\right)
$$

Equation (3) is the objective function, which maximizes the expected profit by choosing the optimal $\vec{\varepsilon}=\left\{\varepsilon_{1}, \ldots, \varepsilon_{J}\right\}$. The expected profit is equal to the expected revenue generated by the contract manufacturer (1) minus the expected penalty costs (2). We solve this model by a full search of the decision space $\vec{\varepsilon}$.

\subsection{Operational planning model}

In this section, we discuss the lower decision level, where the short-term (say monthly) acceptance and production decisions are made based on the operational planning model. The optimal $\vec{\varepsilon}, \theta_{j}$, and $\theta_{s}$ that have been determined at the higher decision level are input to the operational planning model.

The operational planning process is as follows. At time period $t$, the contract manufacturer receives from all outsourcers the capacity reservations $r_{j}(t)$. In the same period $t$, the contract manufacturer decides on the quantity to accept $a_{j}(t)$ based on the following procedure:

1. Accept from all outsourcers $j: a_{j}^{1}(t)=\min \left\{r_{j}(t), \theta_{j}\right\}$

2. Determine $\xi(t)=\theta_{s}-\sum_{j=1}^{J} a_{j}^{1}(t)$ and $\psi_{j}(t)=r_{j}(t)-a_{j}^{1}(t)$ for all $j$. If $\xi(t)>0$ and $\psi_{j}(t)>0$, then go to step 3. Otherwise $a_{j}(t)=a_{j}^{1}(t)$.

3. Distribute $\xi(t)$ over $\psi_{j}(t)$ by giving priority to outsourcer $j$ with the highest expected profit. 
Note that $a_{j}(t)$ can be higher than $\theta_{j}$, dependent on the reservation quantities of the other outsourcers. After having determined $a_{j}(t)$, this is communicated to outsourcer $j$. One period later, the orders follow, which cannot exceed the accepted quantity from the previous period: $q_{j}(t) \leq$ $a_{j}(t-1)$. Knowing the order quantities $q_{j}(t)$, the contract manufacturer decides on the production quantity $p_{j}(t)$ based on the following optimization model (4)-(6), where $(\cdot)^{+}=\max \{\cdot, 0\}$.

$$
\begin{gathered}
\operatorname{Max}\left(\sum_{j=1}^{J} \tau_{j}\left(\varepsilon_{j}, \sigma_{j}\right) q_{j}(t)-\beta \sum_{j=1}^{J}\left(q_{j}(t)-p_{j}(t)\right)^{+}\right) \\
\sum_{j=1}^{J} p_{j}(t) \leq C \\
0 \leq p_{j}(t) \leq q_{j}(t)\left(\leq a_{j}(t-1)\right)
\end{gathered}
$$

The operational planning model (4)-(6) is solved after observing $r_{j}(t)$ and $q_{j}(t)$. Then, the performance of the system can be measured by: the capacity utilization: $\rho_{t}=\frac{1}{c} \sum_{j=1}^{J} p_{j}(t)$, the acceptance rate: $\alpha_{j}(t)=\frac{a_{j}(t)}{r_{j}(t)}$, and the service level: $\gamma_{j}(t)=\frac{p_{j}(t)}{q_{j}(t)}$.

By solving the operational planning model for a large number of periods, the expected performance measures can be determined (7)-(9).

$$
\begin{gathered}
\rho=\lim _{M \rightarrow \infty} \frac{1}{M} \sum_{t=1}^{M}\left(\frac{1}{C} \sum_{j=1}^{J} p_{j}(t)\right) \\
\alpha_{j}=\lim _{M \rightarrow \infty} \frac{1}{M} \sum_{t=1}^{M}\left(\frac{a_{j}(t)}{r_{j}(t)}\right) \\
\gamma_{j}=\lim _{M \rightarrow \infty} \frac{1}{M} \sum_{t=1}^{M}\left(\frac{p_{j}(t)}{q_{j}(t)}\right)
\end{gathered}
$$

\subsection{Consistency between the two decision levels}

In this section, we discuss the consistency between the two decision levels. At the higher level, we determine the optimal capacity flexibility allocation by assuming that all demand larger than $\theta_{j}$ will be rejected. Indeed, the contract manufacturer is not obliged to accept demand larger than $\theta_{j}$, but at the operational planning level (see section 3.2), it is possible that the contract manufacturer accepts from outsourcer $j$ demands larger than $\theta_{j}$ if $\xi(t)$ and $\psi_{j}(t)$ are both positive. Consequently, there is some inconsistency between the two decision levels. The decisions taken at the higher level are 'conservative', as they do not incorporate the possibility of accepting demand larger than $\theta_{j}$, i.e. the higher decision level overestimates the rejected quantities. Therefore, we adapt the objective function of the higher decision level by introducing $\delta$ which takes initially the value of 1 (see equation $3^{\prime}$ ). Then, after solving the operational planning model, we adapt $\delta$ iteratively till the inconsistency is negligible. In section 5 , we show some numerical results for the level of $\delta$. 


$$
\operatorname{Max} \pi(\vec{\varepsilon})=\left(\sum_{j=1}^{J} \tau_{j}\left(\varepsilon_{j}, \sigma_{j}\right) \mu_{j}^{\prime}-\beta \delta \sum_{x=C+1}^{\theta_{S}} x f_{s}^{\prime}(x \mid \vec{\varepsilon})\right)
$$

\section{Numerical results}

In this section, we discuss the numerical results that we gathered by solving the two-level hierarchical planning model that is presented in the previous section. We consider the case with 3 outsourcers $(=3)$ with $\mu_{j}=10$. However, they have different levels of demand uncertainty: $\sigma_{3}>\sigma_{2}>$ $\sigma_{1}$. We consider the unit revenue function as given in 10 . This unit revenue function has been developed, based on the following criteria:

- the unit revenue function $\tau_{j}$ should be an increasing function in $\varepsilon_{j}$ and $\sigma_{j}$ and it takes a nonzero value when $\varepsilon_{j}=0$;

- the incremental increase of the unit revenue should be decreasing in $\varepsilon_{j}$. In other words, the outsourcers pay less extra for additional allocation of capacity flexibility.

$$
\tau_{j}\left(\varepsilon_{j}, \sigma_{j}\right)=\tau_{j}^{\max }\left(\sigma_{j}\right)-\frac{\sigma_{j}}{\varepsilon_{j}+1}
$$

Figure 4 shows the structure of the unit revenue function (10) for the less uncertain outsourcer (the solid line) and for the more uncertain outsourcer (dotted line). Both outsourcers pay a higher unit price when $\varepsilon_{j}$ increases, but the more uncertain outsourcer pays even more for an additional $\varepsilon_{j}$. Table 2 shows the parameters that we vary in the numerical study and their possible values.

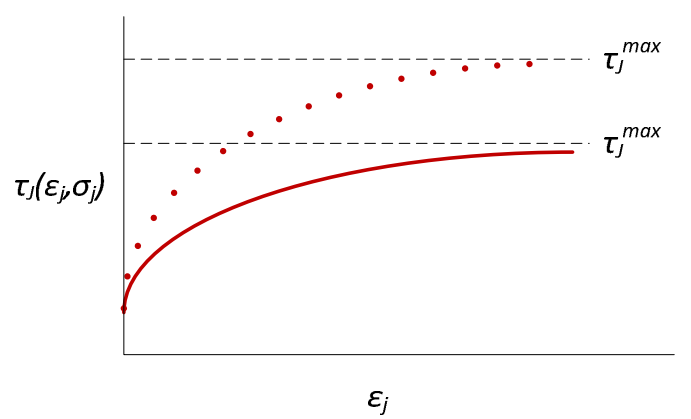

Figure 4. The structure of the unit revenue function for the less uncertain outsourcer (solid line) and the more uncertain outsourcer (dotted line).

Table 2. Set of possible values in the experimental study

\begin{tabular}{c|c} 
Parameter & Possible values \\
\hline$\left\{\sigma_{1}, \sigma_{2}, \sigma_{3}\right\}$ & $\{1,2,3\} ;\{1,3,5\}$ \\
\hline$\tau_{j}^{\max }\left(\sigma_{j}\right)$ & $\{5,6.25,7.5,10\}$ if $\sigma_{j}=\{1,2,3,5\}$ \\
\hline$C$ & $\{28 ; \ldots ; 40\}$ \\
\hline$\beta$ & $\{1 ; 2 ; 5 ; 10 ; \infty\}$
\end{tabular}

In the numerical study, we construct a number of experiments and we are specifically interested in the effects of:

1. different capacity levels on the optimal allocation of flexibility quantities in case of very high penalty cost (section 4.1);

2. different penalty costs on the optimal allocation of flexibility quantities (section 4.2);

3. the allocation of capacity flexibility on the operational performance of the system (section 4.3);

In section 5, we discuss the numerical results of the inconsistency between the two decision levels. 


\subsection{Varying the capacity level}

In this experiment, we consider the case where $\beta \gg \tau_{j}^{\max }\left(\sigma_{j}\right)$, i.e., the extra revenue generated by allocating more flexibility is always lower than the penalty costs (see revenue function 10). It is obvious that in this case, the allocation of capacity flexibility will cumulatively never exceed the capacity level. Still, the question remains how the allocation of the optimal flexibility quantities will be divided over the outsourcers for different capacity levels. Figures 5 and 6 show the optimal allocation quantities $\vec{\varepsilon}$ for $C=28, \ldots, 40$ and $\beta=\infty$. Figure 5 shows the results in case $\left\{\sigma_{1}, \sigma_{2}, \sigma_{3}\right\}=\{1,2,3\}$ and Figure 6 in case $\left\{\sigma_{1}, \sigma_{2}, \sigma_{3}\right\}=\{1,3,5\}$.

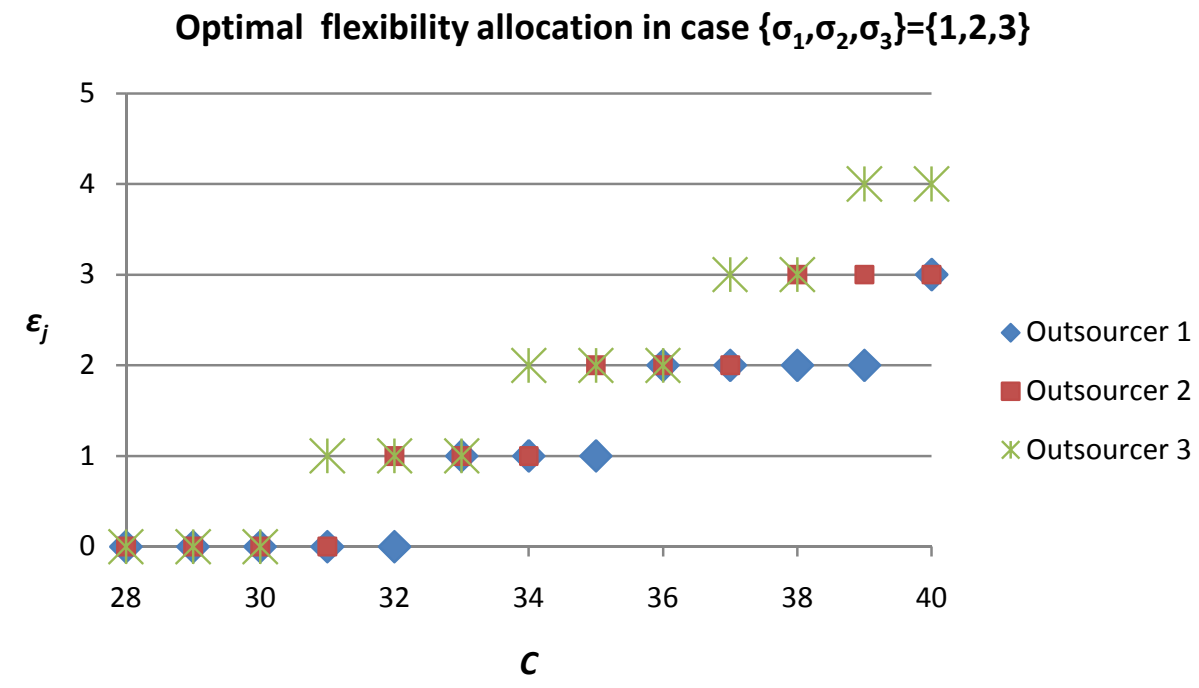

Figure 5. Optimal capacity flexibility allocation in case $\beta=\infty$ and $\left\{\sigma_{1}, \sigma_{2}, \sigma_{3}\right\}=\{1,2,3\}$.

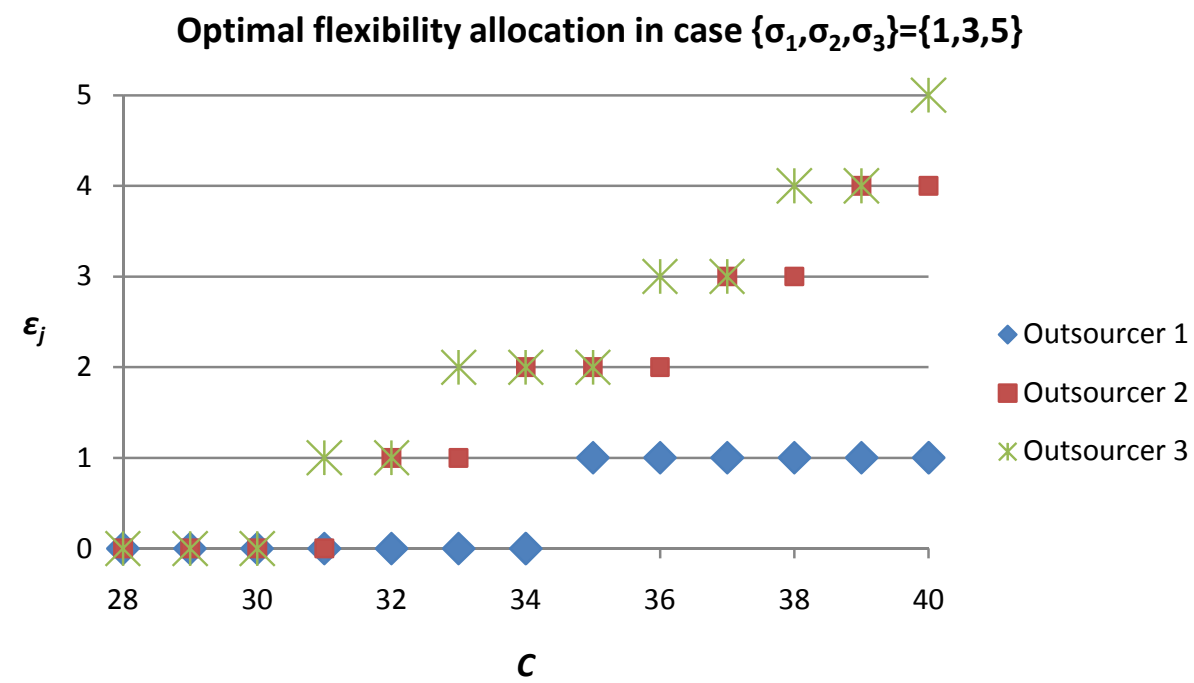

Figure 6. Optimal capacity flexibility allocation in case $\beta=\infty$ and $\left\{\sigma_{1}, \sigma_{2}, \sigma_{3}\right\}=\{1,3,5\}$.

In case $C \leq 30$ (=expected total demand), the optimal capacity allocation is zero, as offering capacity flexibility is not profitable due to the high penalty costs. When $C=30+x$ with $x>0$, exactly $x$ capacity flexibility is allocated as shown in Figures 5 and 6 . The allocation is done to the outsourcer that generates the highest additional expected profit when the capacity level increases with $x$. We see that when the capacity level increases, the more uncertain outsourcer gets at least as much 
capacity flexibility allocated as the less uncertain one: $\varepsilon_{3} \geq \varepsilon_{2} \geq \varepsilon_{1}$. That is due to the fact that the most uncertain outsourcer is willing to pay the most for the additional capacity flexibility, which turns out to be the most profitable option for the contract manufacturer.

\subsection{Varying the unit penalty cost}

In this experiment, we vary the unit penalty cost $\beta$ at different capacity levels $C$ to study the effect on the optimal allocation of capacity flexibility, given the revenue function of (10). We consider two cases with respect to the level of demand uncertainty: $\left\{\sigma_{1}, \sigma_{2}, \sigma_{3}\right\}=\{1,2,3\}$ and $\left\{\sigma_{1}, \sigma_{2}, \sigma_{3}\right\}=\{1,3,5\}$. See Table 3 for the results of this experiment.

Table 3. Optimal capacity flexibility allocation for different values of $\beta$ and $C$

\begin{tabular}{|c|c|c|c|c|c|c|c|c|c|c|c|}
\hline $\multicolumn{6}{|c|}{\sigma_{1}, \sigma_{2}, \sigma_{3}}=\{1,2,3\}$ & $\multicolumn{6}{|c|}{\sigma_{1}, \sigma_{2}, \sigma_{3}}=\{1,3,5\}$ \\
\hline$C$ & $\beta$ & $\varepsilon_{1}$ & $\varepsilon_{2}$ & $\varepsilon_{3}$ & $\pi(\vec{\varepsilon})$ & $C$ & $\beta$ & $\varepsilon_{1}$ & $\varepsilon_{2}$ & $\varepsilon_{3}$ & $\pi(\vec{\varepsilon})$ \\
\hline \multirow[t]{4}{*}{28} & 1 & 0 & 0 & 1 & 79.71 & \multirow[t]{4}{*}{28} & 1 & 0 & 1 & 2 & 101.62 \\
\hline & 2 & 0 & 0 & 1 & 70.51 & & 2 & 0 & 1 & 1 & 94.56 \\
\hline & 5 & 0 & 0 & 0 & 45.59 & & 5 & 0 & 0 & 1 & 75.09 \\
\hline & 10 & 0 & 0 & 0 & 8.35 & & 10 & 0 & 0 & 0 & 47.68 \\
\hline \multirow[t]{4}{*}{29} & 1 & 0 & 1 & 1 & 96.13 & \multirow[t]{4}{*}{29} & 1 & 0 & 1 & 3 & 113.51 \\
\hline & 2 & 0 & 0 & 1 & 91.66 & & 2 & 0 & 1 & 2 & 108.30 \\
\hline & 5 & 0 & 0 & 0 & 81.19 & & 5 & 0 & 1 & 1 & 92.68 \\
\hline & 10 & 0 & 0 & 0 & 63.74 & & 10 & 0 & 0 & 0 & 75.25 \\
\hline \multirow[t]{4}{*}{30} & 1 & 0 & 1 & 1 & 112.61 & \multirow[t]{4}{*}{30} & 1 & 1 & 1 & 3 & 122.91 \\
\hline & 2 & 0 & 0 & 1 & 108.67 & & 2 & 0 & 1 & 3 & 119.45 \\
\hline & 5 & 0 & 0 & 0 & 106.98 & & 5 & 0 & 1 & 1 & 117.05 \\
\hline & 10 & 0 & 0 & 0 & 105.91 & & 10 & 0 & 0 & 0 & 114.98 \\
\hline \multirow[t]{4}{*}{31} & 1 & 0 & 1 & 1 & 126.03 & \multirow[t]{4}{*}{31} & 1 & 1 & 1 & 3 & 131.65 \\
\hline & 2 & 0 & 0 & 1 & 122.88 & & 2 & 0 & 1 & 3 & 128.69 \\
\hline & 5 & 0 & 0 & 1 & 121.67 & & 5 & 0 & 1 & 1 & 126.74 \\
\hline & 10 & 0 & 0 & 1 & 121.06 & & 10 & 0 & 0 & 1 & 125.79 \\
\hline \multirow[t]{4}{*}{32} & 1 & 0 & 1 & 2 & 137.45 & \multirow[t]{4}{*}{32} & 1 & 1 & 2 & 3 & 143.09 \\
\hline & 2 & 0 & 1 & 1 & 135.41 & & 2 & 0 & 2 & 3 & 140.25 \\
\hline & 5 & 0 & 1 & 1 & 134.39 & & 5 & 0 & 1 & 2 & 139.06 \\
\hline & 10 & 0 & 1 & 1 & 134.01 & & 10 & 0 & 1 & 1 & 138.98 \\
\hline
\end{tabular}

The results show a number of insights. First, the optimal allocation of capacity flexibility is rather sensitive to $\beta$. The higher the $\beta$, the lower the optimal capacity flexibility quantities. Moreover, when the level of demand uncertainties is higher $\left(\left\{\sigma_{1}, \sigma_{2}, \sigma_{3}\right\}=\{1,3,5\}\right)$, the optimal capacity flexibility quantities are higher, as the increased risk is then compensated by an increased allocation of capacity flexibility, which generates higher revenue. Furthermore, when the capacity level is higher, the expected profit increases, but also the optimal capacity flexibility quantities increases, as it is less risky to allocate more capacity flexibility.

\subsection{The operational performance}

In this section, we focus on the lower decision level that has been introduced and discussed in section 3.2. The optimal capacity flexibility quantities that we determined at the higher decision level are input to the lower decision level, the operational planning model. We simulate the operational planning model to measure the performance of the production line in terms of capacity utilization $\rho$ (equation 7), the acceptance rate $\alpha_{j}$ (eq. 8), and the service level $\gamma_{j}$ (eq. 9). The simulation length is 1000 periods and the number of replications is 3 . The simulation results showed negligible variance in the performance measures. In this simulation study, we consider the unit revenue function as given in (10). Table 4 shows the simulation results for $C=\{28, \ldots, 32\}$ and 
$\beta=\{1 ; 2 ; 5 ; 10\}$ in case $\left\{\sigma_{1}, \sigma_{2}, \sigma_{3}\right\}=\{1,3,5\}$. The table shows the average capacity utilization, the average acceptance rates for the 3 outsourcers, and their service levels.

\begin{tabular}{|c|c|c|c|c|c|c|c|c|c|c|}
\hline & & & & & & & & & & \\
\hline$C$ & $\beta$ & $\vec{\varepsilon}$ & $\pi(\vec{\varepsilon})$ & $\rho$ & $\alpha_{1}$ & $\alpha_{2}$ & $\alpha_{3}$ & $\gamma_{1}$ & $\gamma_{2}$ & $\gamma_{3}$ \\
\hline \multirow[t]{4}{*}{28} & 1 & $(0,1,2)$ & 103.79 & 0.90 & 1.00 & 1.00 & 1.00 & 0.78 & 0.98 & 1.00 \\
\hline & 2 & $(0,1,1)$ & 97.59 & 0.90 & 0.99 & 0.98 & 0.96 & 0.83 & 0.99 & 1.00 \\
\hline & 5 & $(0,0,1)$ & 81.19 & 0.90 & 0.99 & 0.95 & 0.93 & 0.86 & 1.00 & 1.00 \\
\hline & 10 & $(0,0,0)$ & 61.49 & 0.89 & 0.97 & 0.91 & 0.87 & 0.92 & 1.00 & 1.00 \\
\hline \multirow[t]{4}{*}{29} & 1 & $(0,1,3)$ & 114.82 & 0.88 & 1.00 & 1.00 & 1.00 & 0.85 & 0.99 & 1.00 \\
\hline & 2 & $(0,1,2)$ & 110.56 & 0.88 & 1.00 & 0.98 & 0.97 & 0.86 & 1.00 & 1.00 \\
\hline & 5 & $(0,1,1)$ & 97.12 & 0.87 & 0.99 & 0.96 & 0.94 & 0.87 & 1.00 & 1.00 \\
\hline & 10 & $(0,0,0)$ & 91.06 & 0.87 & 0.98 & 0.92 & 0.90 & 1.00 & 1.00 & 1.00 \\
\hline \multirow[t]{4}{*}{30} & 1 & $(1,1,3)$ & 123.61 & 0.86 & 1.00 & 1.00 & 1.00 & 0.99 & 1.00 & 1.00 \\
\hline & 2 & $(0,1,3)$ & 120.76 & 0.86 & 1.00 & 0.98 & 0.98 & 1.00 & 1.00 & 1.00 \\
\hline & 5 & $(0,1,1)$ & 120.61 & 0.85 & 0.99 & 0.97 & 0.96 & 1.00 & 1.00 & 1.00 \\
\hline & 10 & $(0,0,0)$ & 119.92 & 0.84 & 0.99 & 0.94 & 0.92 & 1.00 & 1.00 & 1.00 \\
\hline \multirow[t]{4}{*}{31} & 1 & $(1,1,3)$ & 132.04 & 0.83 & 1.00 & 1.00 & 1.00 & 1.00 & 1.00 & 1.00 \\
\hline & 2 & $(0,1,3)$ & 129.41 & 0.83 & 1.00 & 0.99 & 0.98 & 1.00 & 1.00 & 1.00 \\
\hline & 5 & $(0,1,1)$ & 129.17 & 0.82 & 1.00 & 0.97 & 0.96 & 1.00 & 1.00 & 1.00 \\
\hline & 10 & $(0,0,1)$ & 128.63 & 0.82 & 0.99 & 0.96 & 0.94 & 1.00 & 1.00 & 1.00 \\
\hline \multirow[t]{4}{*}{32} & 1 & $(1,2,3)$ & 143.24 & 0.81 & 1.00 & 1.00 & 1.00 & 1.00 & 1.00 & 1.00 \\
\hline & 2 & $(0,2,3)$ & 140.59 & 0.81 & 1.00 & 1.00 & 1.00 & 1.00 & 1.00 & 1.00 \\
\hline & 5 & $(0,1,2)$ & 140.38 & 0.80 & 1.00 & 1.00 & 0.98 & 1.00 & 1.00 & 1.00 \\
\hline & 10 & $(0,1,1)$ & 139.42 & 0.80 & 1.00 & 0.97 & 0.94 & 1.00 & 1.00 & 1.00 \\
\hline
\end{tabular}

The results show that the higher the unit penalty cost $\beta$, the lower the acceptance rate, but the higher the service level. In other words, when the penalty cost increases, less reservations are accepted (so less risk is taken), but a larger fraction of the order is produced. This result holds for all considered capacity levels. The results also show that $\alpha_{1} \geq \alpha_{2} \geq \alpha_{3}$, i.e., priority is given to the less uncertain outsourcer when the acceptance decision is taken, whereas we see the opposite effect with the service levels, namely $\gamma_{1} \leq \gamma_{2} \leq \gamma_{3}$. The latter is because the most uncertain outsourcer generates the highest unit revenue (see eq. 4), which explains the priority to the most uncertain outsourcer. Thus, when orders are placed, it is optimal to give priority to the most uncertain (and most paying) outsourcer, whereas when reservations are placed, priority should be given to the most certain outsourcer. We conducted the same experiment in case $\left\{\sigma_{1}, \sigma_{2}, \sigma_{3}\right\}=\{1,2,3\}$ and the insights are the same as in case $\left\{\sigma_{1}, \sigma_{2}, \sigma_{3}\right\}=\{1,3,5\}$. 


\section{Consistency between the two decision levels}

In the previous section, we discussed the numerical results of the two decision levels separately. As discussed in section 3.3, there is some inconsistency between the two decision levels. The inconsistency is due to the overestimation of the rejected quantities at the higher decision level. Therefore, we adapt the objective function of the higher decision level model by introducing the parameter $\delta$ in the objective function (see eq. $3^{\prime}$ ). In this numerical study, we determine $\delta$ by reducing its value iteratively from 1 until consistency is achieved between the two levels, i.e., the estimated rejected quantities are equal. Figure 7 shows the values of $\delta$ for different $\beta$ and $C$. We see that the higher $\beta$, the lower $\delta$, i.e., the higher the inconsistency. That means that more correction is needed to compensate for the effect of rejecting all demand larger than $\theta_{j}$. For the same reason, the opposite effect holds for $C$, i.e., the higher $C$, the higher $\delta$.

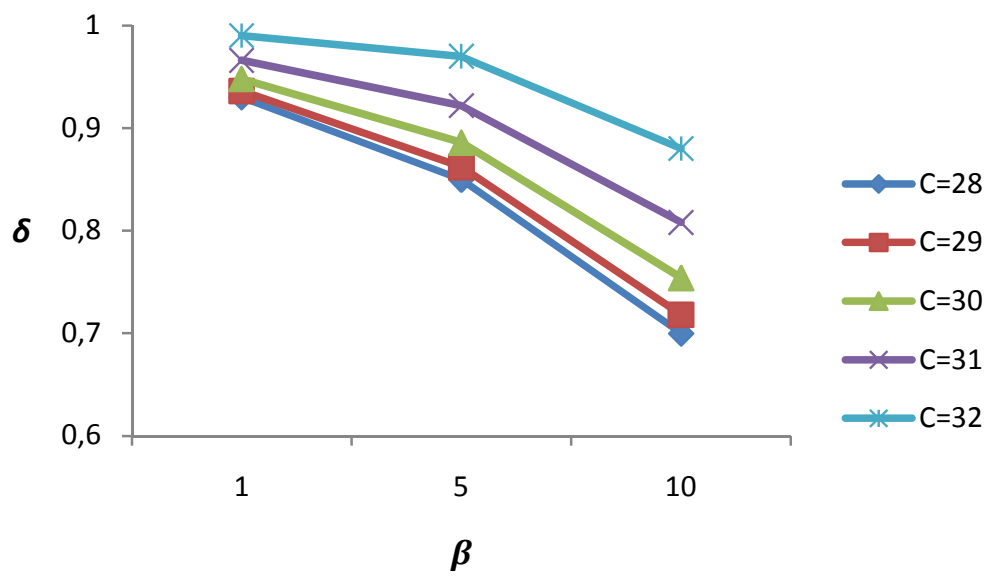

Figure 7. The value of $\delta$ for different $\beta$ and $C$, and $\left\{\sigma_{1}, \sigma_{2}, \sigma_{3}\right\}=\{1,3,5\}$

Since the inconsistency is the highest in case of high $\beta$ and small $C$, we show in Table 5 the consequence of the inconsistency on the optimal capacity flexibility quantities and on the expected profit. Moreover, we also show in table 5 the initially and updated expected rejected rate $\sum_{j=1}^{J}\left(1-\alpha_{j}\right)$. We see that indeed for low levels of $C$ and high levels of $\beta$, the updated $\vec{\varepsilon}$ changes the most, whereas when the capacity is sufficient, the optimal capacity flexibility allocation hardly changes. Table 5 also shows the initial and updated profit levels. We see that the inconsistency is the highest when $\beta$ is high and $C$ is small.

Table 5. The effect of inconsistency on the optimal capacity flexibility allocation in case $\left\{\sigma_{1}, \sigma_{2}, \sigma_{3}\right\}=\{1,3,5\}$

\begin{tabular}{c|c|c|c|c|c|c|c}
$\boldsymbol{C}$ & $\boldsymbol{\beta}$ & $\overrightarrow{\boldsymbol{\varepsilon}}$ initial & $\boldsymbol{\Sigma ( 1 - \alpha _ { j } ) \text { initial }}$ & $\boldsymbol{\pi}(\overrightarrow{\boldsymbol{\varepsilon}})$ initial & $\overrightarrow{\boldsymbol{\varepsilon}}$ update & $\boldsymbol{\Sigma}\left(\mathbf{1 - \alpha} \boldsymbol{\alpha}_{j}\right)$ update & $\boldsymbol{\pi}(\overrightarrow{\boldsymbol{\varepsilon}})$ update \\
\hline 28 & 5 & $(0,0,1)$ & 0.13 & 75.09 & $(0,1,1)$ & 0.10 & 80.69 \\
\hline & 10 & $(0,0,0)$ & 0.25 & 47.68 & $(0,1,1)$ & 0.16 & 60.85 \\
\hline 29 & 5 & $(0,1,1)$ & 0.11 & 92.68 & $(0,1,1)$ & 0.09 & 96.59 \\
\hline & 10 & $(0,0,0)$ & 0.20 & 75.25 & $(0,0,1)$ & 0.15 & 90.89 \\
\hline 30 & 5 & $(0,1,1)$ & 0.08 & 117.05 & $(0,1,1)$ & 0.08 & 120.23 \\
\hline & 10 & $(0,0,0)$ & 0.15 & 114.98 & $(0,0,0)$ & 0.13 & 119.81
\end{tabular}




\section{Conclusions}

In this paper, we study the case where a contract manufacturer serves a number of outsourcers with different levels of demand uncertainty on the same capacitated production line. For capacity planning purposes, the contract manufacturer requires that all outsourcers reserve capacity before placing orders. The contract manufacturer collects the reservations and decides on the accepted reservation quantity, which bounds the order quantity that follows later on. The contract manufacturer is not willing to accept all uncertainty from the outsourcers and therefore, the contract manufacturer wants to offer each outsourcer a contract that describes how much capacity flexibility is allocated to that outsourcer, which is the amount of demand that the contract manufacturer will always accept from the outsourcers. We assume that the more capacity flexibility offered (to more uncertain outsourcer), the higher the unit revenue for the contract manufacturer.

We developed a hierarchical model that consists of two decision levels. At the higher level, the optimal capacity flexibility allocation is determined (which is a contract parameter) by maximizing the expected profit function and by anticipating on the performance at the operational level. The capacity flexibility quantities are input to the lower decision level where the operational planning decisions are made and demands (reservations and orders) are observed. We perform a numerical study, which reveals several interesting managerial insights. First, the allocation of capacity flexibility is very sensitive to the unit penalty cost. The higher the unit penalty cost, the lower the capacity flexibility allocation. For an outsourcer, this implies that by setting the penalty cost very high, he can secure his commitment, but - on the contrary - will get less flexibility, as the contract manufacturer would want to limit his risk that is caused by providing flexibility. Consequently, for an outsourcer facing uncertain demand, it may not be a good strategy to set high penalty cost, as he will get little flexibility.

Second, for a wide range of capacity levels and unit penalty costs, the more uncertain outsourcer gets at least the same and often more capacity flexibility allocated than the less uncertain outsourcer. In practice, managers often give priority and rewards to the least uncertain outsourcer, but our study gives the opposite insight, provided that the more uncertain outsourcer is willing to pay extra for additional allocation of capacity flexibility. So, paying a little extra for flexibility appears to pay-off in terms of getting flexibility guarantees. For the outsourcer, this may result into lower inventory levels (cf. Boulaksil and Fransoo, 2009).

The third insight comes from simulating the operational planning process. We have seen that when making the acceptance decision (given the allocated capacity flexibility decision), priority is given to the less uncertain outsourcer, because allocating capacity flexibility to that outsourcer generates the highest expected profit. The information from the less uncertain outsourcer seems to be the most valuable, whereas accepting more from the more uncertain outsourcer is risky due to the uncertainty of its demand. However, we see the opposite effect when placing orders (after the acceptance decision has been made), namely that priority is given to the more uncertain outsourcer. Now the order is placed, no risk is involved anymore and priority is given the outsourcer that generates the highest unit revenue, which is the most uncertain outsourcer.

The last part of the numerical study deals with the inconsistency between the two decision levels. At the higher decision level, we assume that all demand larger than contractually agreed upon is rejected, whereas at the operational level, more demand can be accepted, dependent on the other outsourcers. Therefore, we propose a feedback loop from the lower decision level to the higher decision level to eliminate the inconsistency between the two decision levels. Without this feedback, i.e., without the hierarchical integration, the capacity flexibility quantities are too conservative, 
especially when the unit penalty cost is high and the capacity is tight. Therefore, the hierarchical integration and anticipation approach is required.

In this paper, we assume a make-to-order system for the contract manufacturer with no possibility of producing on stock. An idea for future research would be to allow the contract manufacturer to produce on stock, based on forecasts from the outsourcers. This might be interesting, as the contract manufacturer does not fully utilize its production capacity. Another extension would be to consider the case where the demands from the different outsourcers are correlated, which reflects the real-life situation better, as the outsourcers are likely to operate in the same market. 


\section{References}

Beach, R., Muhlemann, A.P., Price, D.H.R., Paterson, A., and Sharp, J.A. (2000), A review of manufacturing flexibility, European Journal of Operational Research, 122, 41-57.

Beamon, B.M. (1999) Measuring supply chain performance, International Journal of Operations and Production Management, 19, 3, 275-292.

Bertrand, J.W.M. (2003), Supply chain design: flexibility considerations, Ch. 4, in A.G. de Kok and S.C. Graves (eds.), Handbook in Operations Research and Management Science: design, coordination, and operation, Vol. 11, Amsterdam, the Netherlands.

Bish, E.K., Muriel, A., Biller, S. (2005), Managing flexible capacity in a make-to-order environment, Management Science, 51, 2, 167-180.

Bryce, D.J. and Useem, M. (1998), The impact of corporate outsourcing on company value, European Management Journal, 16, 635-643.

Boulaksil, Y. and Fransoo, J.C. (2008), Strategic and operational outsourcing - decisions in the pharmaceutical industry, BETA working paper 242, Eindhoven University of Technology.

Boulaksil, Y. and Fransoo, J.C. (2009) Order release strategies to control outsourced operations in a supply chain, International Journal of Production Economics, 119, 1, 149-160.

Business Insights (2005), The future of outsourcing: Contract Manufacturing Organizations. http://www.globalbusinessinsights.com/pharmaceutical outsourcing/pharma outsourcing CMO.ht m. Visited on 12 March 2009.

Cachon, G.P. and Lariviere, M.A. (2005), Supply chain coordination with revenue-sharing contracts: Strengths and limitations, Management Science, 51, 1, 30-44.

D'Souza, D.E. and Williams, F.P. (2000), Toward a taxonomy of manufacturing flexibility dimensions, Journal of Operations Management, 18, 577-593.

De Toni, A. and Tonchia, S. (2001), Performance measurement systems: Models, characteristics, and measures, International Journal of Operational and Production Management, 21, 46-70.

Duclos, L.K., Vokurka, R.J., and Lummus, R.R. (2003), A conceptual model of supply chain flexibility, Industrial Management and Data Systems, 103, 6, 446-456.

Eppen, G.D., Martin, R.K., and Schrage, L. (1989), A scenario approach to capacity planning, Operations Research, 37, 4, 517-527.

Frazelle, E. (1986), Flexibility: A strategic response in changing times, Industrial Engineering, 16-20.

Gerwin, D. (1993) Manufacturing flexibility: a strategic perspective, Management Science, 39, 4, 395410.

Gupta, Y.P. and Goyal, S. (1989), Flexibility of manufacturing systems: Concepts and measurement, European Journal of Operational Research, 43, 119-135. 
Kulatilaka, N. and Marks, S.G. (1988), The strategic value of flexibility: Reducing the ability to compromise, The American Economic Review, 78, 3, 574-580.

Law, A.M. and Kelton, W.D. (2000), Simulation modelling and analysis, 3rd edition, McGraw-Hill, New-York.

Liston, P., Byrne, J, Byrne, P.J., and Heavey, C. (2007), Contract costing in outsourcing enterprises: Exploring the benefits of discrete-event simulation, International Journal of Production Economics, $110,97-114$.

Markowitz, H. (1952), Portfolio selection, The Journal of Finance, 7, 1, 77-91.

Pardalos, P.M., Sandström, M., and Zopounidis, C. (1994), On the use of optimization models for portfolio selection: a review and some computational results, Computational Economics, 7, 227-244.

Sanchez, A.M. and Perez, M.P. (2005) Supply chain flexibility and firm performance, International Journal of Operations and Production Management, 25, 7, 681-700.

Sethi, A.K. and Sethi, S.P. (1990), Flexibility in manufacturing, The International Journal of Flexible Manufacturing Systems, 2, 289-328.

Shah, N. (2004), Pharmaceutical supply chains: key issues and strategies for optimisation, Computers \& Chemical Engineering, 28, 929-941.

Slack, N. (2005), The flexibility of manufacturing systems, International Journal of Operations and Production Management, 25, 12, 1190-1200.

Tsay, A.A. (1999), The quantity flexibility contract and supplier-customer incentives, Management Science, 45, 10, 1339-1358.

Van Mieghem, J.A. (1998), Investment strategies for flexible resourcers, Management Science, 44, 8, 1071-1078. 